\section{Plasma proteins in meconium from normal infants and from babies with cystic fibrosis}

Meconium from babies with cystic fibrosis (CF) has been shown by Green and Shwachman (1968) to contain readily detectable amounts of albumin. Screening for the disease is therefore possible by testing meconium specimens for the presence of albumin with albustix or Boehringer test tape. Any screening procedure, however, requires the availability of reliable methods for checking positive and doubtful results; for this reason, we have investigated the plasma proteins in meconium specimens from a series of normal babies and from two infants with CF.

\section{Materials and methods}

Meconium specimens. Meconium specimens were collected from 20 normal infants, who were subsequently found to have a normal concentration of salt in their sweat, and from 2 babies (Cases 1 and 2 in Table) both of whom were suffering from meconium ileus; the diagnosis of CF was confirmed in both these patients on the basis of an above normal concentration of salt in sweat. The specimens were frozen and lyophilized as soon as they were received; none was visibly contaminated with blood. Aqueous extracts were prepared for electrophoresis by making suspensions of dried normal meconium in $0.05 \mathrm{~mol} / \mathrm{l}$. tris acetate buffer, $p \mathrm{H} 7 \cdot 3$, containing $0.3 \mathrm{~mol} / 1 . \mathrm{NaCl}$ and $0.1 \mathrm{~mol} / 1$. EDTA; none of the extracts was blood-stained. The suspensions were stirred intermittently for $30 \mathrm{~min}$ with a vortex mixer after which the insoluble material was removed by centrifuging at $3000 \times g$ for $30 \mathrm{~min}$.

Proteolytic digests of $\mathrm{CF}$ meconium from one patient were prepared by making $25 \mathrm{mg} / \mathrm{ml}$ suspensions of the dried meconium in $0.046 \mathrm{~mol} / \mathrm{l}$. tris acetate buffer, $p \mathrm{H}$ $8 \cdot 1$, containing $0 \cdot 01 \mathrm{~mol} / 1$. $\mathrm{CaCl}_{2}$ and $2 \mathrm{mg} / \mathrm{ml}$ trypsin, and in $0.01 \mathrm{~mol} / 1$. $\mathrm{HCl}$ containing $2 \mathrm{mg} / \mathrm{ml}$ pepsin; 25 $\mathrm{mg} / \mathrm{ml}$ control suspensions of the meconium were also made in these solutions but without enzymes. Toluene was added as preservative to the four suspensions which were incubated for 24 hours at $37^{\circ} \mathrm{C}$; insoluble material was removed by centrifuging.

Electrophoresis. $5 \mu 1$ volumes of meconium extracts were separated on cellulose acetate strip in barbitone buffer and the strips stained with Coomassie Blue (Ryley and Brogan, 1973). $4 \mu \mathrm{l}$ volumes of meconium extracts were subjected to antigen-antibody crossed immunoelectrophoresis by a modification of the method of Clarke and Freeman (1968) that has been described by one of us in some detail (Ryley, 1972). Identification of protein arcs was carried out with specific antisera and the concentrations of some of the plasma proteins estimated by measuring the areas subtended by their arcs (Ryley and Brogan, 1973). $\alpha_{1}$-Antitrypsin, IgA, and IgG were estimated by the electroimmunoassay method of Lopez, Tsu, and Hyslop (1969) using monospecific antisera.

\section{Results}

Aqueous extracts of meconium from 19 of the normal infants separated on cellulose acetate into diffuse bands with mobilities within the range of the $\alpha$ - and $\gamma$-globulins, and no discrete bands could be distinguished; the extract of the specimen from one normal baby, however, produced a heavily staining protein band with $\alpha$-globulin mobility. Extracts from both CF patients gave discrete protein bands with a densely staining line with the same mobility as serum albumin.

When crossed immunoelectrophoresis was carried out on extracts of normal meconium, two peaks were obtained against antihuman serum that were shown to be caused by $\alpha_{1}$-antitrypsin and $\alpha_{1}$-antichymotrypsin (Fig.); a very small anodal arc due to albumin was found when most specimens were tested at $4 \% \mathrm{w} / \mathrm{v}$ concentration. Extracts of meconium specimens from both CF patients, however, produced a number of plasma protein peaks (Fig.) which were shown to be caused by albumin, $\alpha_{1}$-antitrypsin, $\alpha_{1}$-antichymotrypsin, transferrin, $\beta_{1 c}$ globulin, IgA, and IgG. Gc globulin was present in one specimen but $\alpha_{2}-$ macroglobulin, haptoglobin, and caeruloplasmin were detected in neither. Arcs that were probably due to several other plasma proteins were also seen in the immunoelectrophoretic patterns of both CF meconium extracts, but these have not yet been identified. Proteolysis of CF meconium for 24 hours with trypsin or pepsin caused the electrophoretic pattern to become similar to that of normal meconium except that there remained a small but well-defined peak due to albumin.

The concentrations of 7 plasma proteins in the meconium specimens were calculated from the crossed immunoelectrophoretic patterns or from the length of the electroimmunoassay 'rockets' using 

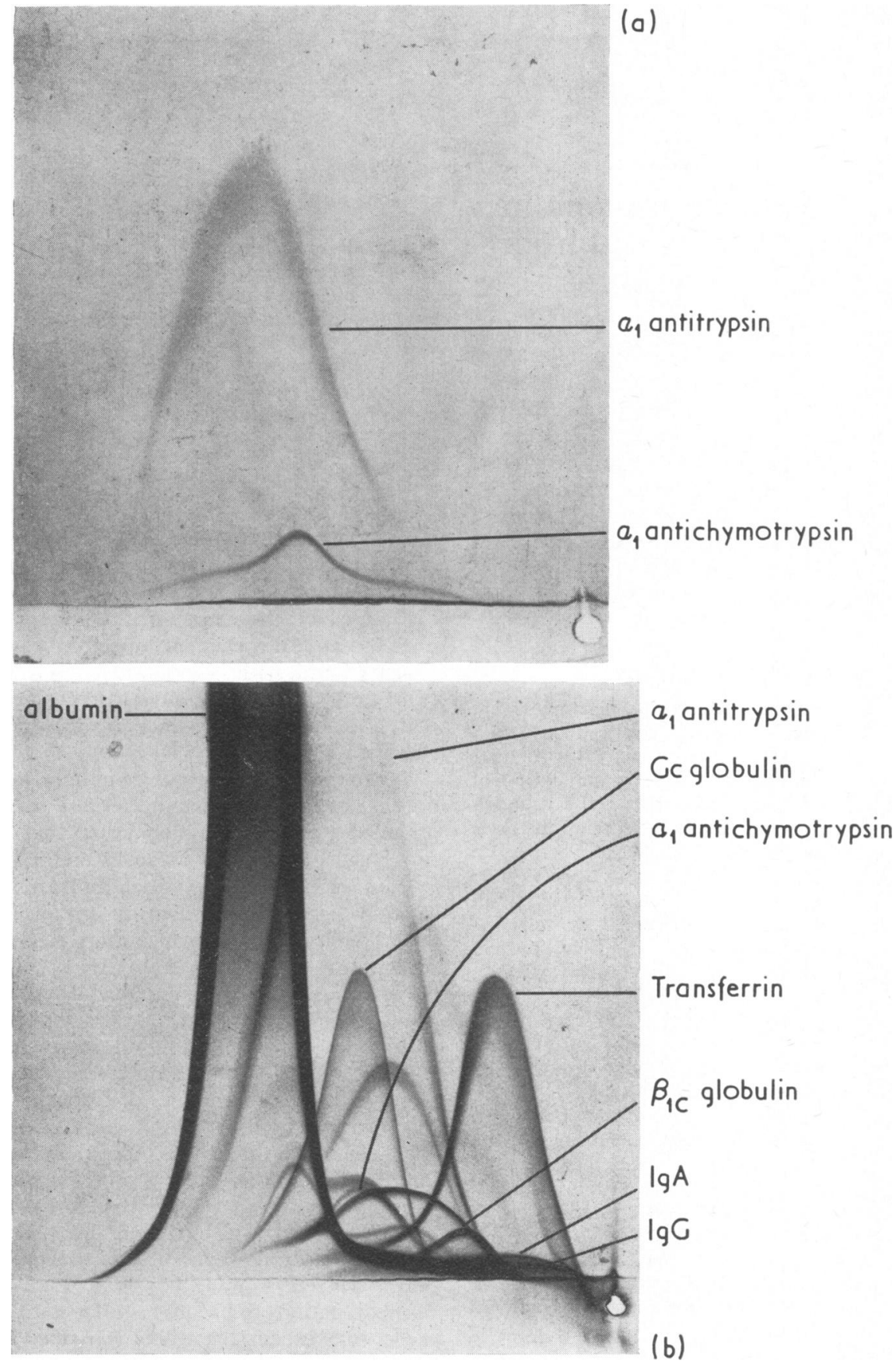

FIG.-Crossed immunoelectrophoretic patterns of aqueous extracts of meconium against rabbit antihuman serum. The protein arcs were stained with Coomassie Blue. (a) Typical pattern produced by extract of normal specimen prepared from a $1 \%$ suspension of freeze-dried meconium showing peaks caused by $\alpha_{1}$-antitrypsin and $\alpha_{1}$-antichymotrypsin. (b) Pattern produced by aqueous extracts of specimen from CF patient (Case 1) prepared from a $1 \%$ suspension of freeze-dried meconium showing peaks caused by albumin, $\alpha_{1}$-antitrypsin, $\alpha_{1}$-antichymotrypsin, Gc globulin, transferrin, $\beta_{1 \mathrm{c}}$ globulin, Ig A, and IgG. 
TABLE

Concentrations of plasma proteins as $\mathrm{mg} / \mathrm{g}$ dry weight in specimens of meconium from 20 normal babies and from 2 patients with $C F$

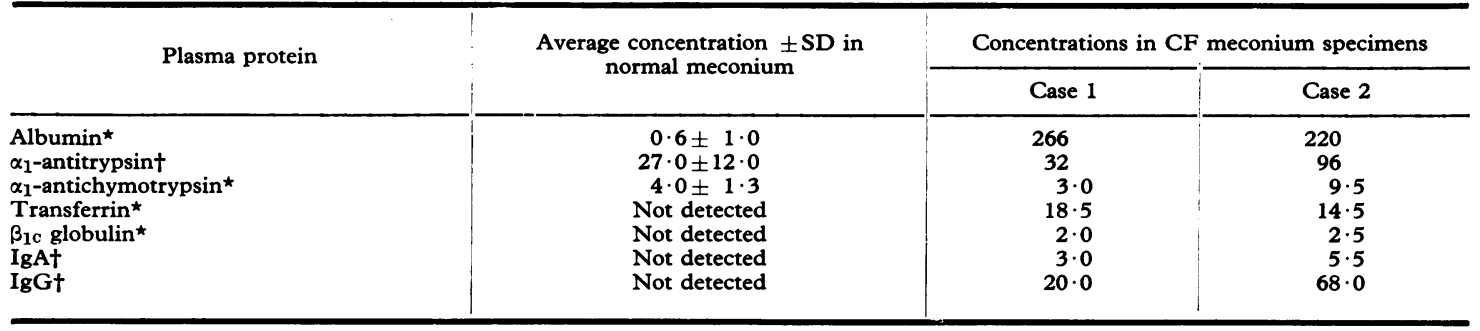

^Concentration calculated from crossed immunoelectrophoresis pattern.

fConcentration calculated by electroimmunoassay using monospecific antiserum.

monospecific antisera. The results are summarized in the Table. Albumin concentrations were determined by crossed immunoelectrophoresis rather than electroimmunoassay because the former method permitted estimation of low concentrations of this plasma protein. However, electroimmunoassay was found to be an invaluable means of determining within 6 hours whether or not albumin was present in above average concentration, since a number of specimens could be examined simultaneously.

\section{Discussion}

It was possible to detect albumin in CF meconium by cellulose strip electrophoresis but one specimen of normal meconium from the group of 20 examined gave a densely staining band with a mobility sufficiently close to albumin to invite confusion of identity. For this reason, we consider that the method is not sufficiently reliable to differentiate clearly between normal and CF meconium. In contrast, quantitative immunoelectrophoresis gave unequivocal results. It was possible to determine simultaneously in a series of meconium extracts whether or not albumin was present in above average concentrations by the use of a method of electroimmunoassay (Lopez et al., 1969) that gave results within 6 hours. Crossed immunoelectrophoresis showed the presence of a number of plasma proteins in CF meconium in contrast with normal meconium specimens, which contained only $\alpha_{1}$-antitrypsin and $\alpha_{1}$-antichymotrypsin together with variable traces of albumin.

The origin of the plasma proteins in CF meconium is a question of great interest. It is unlikely that their presence was the result of extravasation of blood since neither the meconium specimens nor the extracts were blood-stained. It is possible that the plasma proteins of $\mathrm{CF}$ meconium originate from amniotic fluid since this fluid is ingested in quantity by the normal fetus before birth (Pritchard, 1965). When gut enzymes are present in normal concentrations it is likely that these proteins are digested unless they are enzyme inhibitors; when one of the CF specimens was subjected to proteolysis the immunoelectrophoretic pattern largely returned to that characteristic of normal meconium.

Detection of albumin in meconium may hold promise as a method of screening for CF since the technique is simple and inexpensive. We believe, on the basis of our results, that it is possible to reinforce such a screening programme by carrying out quantitative immunoelectrophoresis on all positive or doubtfully positive specimens of meconium and thus provide confirmatory evidence for the diagnosis of this disease.

\section{Summary}

Cellulose acetate strip electrophoresis was found to be not sufficiently reliable to differentiate between normal and CF meconium, but marked differences were obtained when quantitative immunoelectrophoretic methods were employed. Normal meconium was shown to contain $\alpha_{1}$-antitrypsin and $\alpha_{1}$-antichymotrypsin and most samples contained low concentrations of albumin; in contrast, meconium from CF patients contained much higher concentrations of albumin, and measurable amounts of a variety of other plasma proteins. It is suggested that quantitative immunoelectrophoresis could be used as a means of confirming the diagnosis of CF if positive results are obtained when meconium specimens are screened with test strips.

We are grateful to the Cystic Fibrosis Research Trust for financial support. 


\section{REFERENCES}

Clarke, H. G. M., and Freeman, T. (1968). Quantitative immunoelectrophoresis of human serum proteins. Clinical Science, 35, 403.

Green, M. N., and Shwachman, H. (1968). Presumptive tests for cystic fibrosis based on serum protein in meconium. Pediatrics, 41, 989.

Lopez, M., Tsu, T., and Hyslop, N. E. (1969). Studies of electroimmunodiffusion: immunochemical quantitation of proteins in dilute solutions. Immunochemistry, 6, 513.

Pritchard, J. A. (1965). Deglutition by normal and anencephalic fetuses. Obstetrics and Gynaecology, 25, 289.

Ryley, H. C. (1972). An immunoelectrophoretic study of the soluble secretory proteins of sputum. Biochimica Biophysica Acta, 271, 300.

Ryley, H. C., and Brogan, T. D. (1973). Quantitative immunoelectrophoretic analysis of the plasma proteins in the sol phase of sputum from patients with chronic bronchitis. Fournal of Clinical Pathology, 26, 852.

H. C. Ryley, LynNe Neale, T. D. Brogan,* and P. T. BRAY

Departments of Medical Microbiology and Child Health, Welsh National School of Medicine, Cardiff.

*Correspondence to Dr. T. D. Brogan, Department of Medical Microbiology, Welsh National School of Medicine, Heath Park Cardiff CF4 4XN.

\section{Incidence of growth hormone deficiency}

Growth hormone for therapeutic purposes is extracted from human pituitaries. It is of value to those responsible for its preparation to know the approximate incidence of the only conditions for which it is of value, idiopathic growth hormone deficiency and growth hormone deficiency secondary to intracranial disease. This paper explores the evidence about this from the Newcastle upon Tyne region.

\section{Evidence}

Growth clinic patients. Since 1967 a clinic has been held at the Royal Victoria Infirmary at which patients from the Newcastle region requiring growth hormone have been seen regularly. As the major centres of population in the region are separated from other reference hospitals by long distances and large tracts of sparsely populated country, it is likely that these patients comprise all those in the region known to have growth hormone deficiency.

The patients discussed in this paper have all been diagnosed as being deficient in growth hormone on the basis of low serum growth hormone levels after an adequate hypoglycaemic stimulus, and have been accepted into the Medical Research Council growth hormone treatment trial. Children with psychosocial dwarfism associated with low serum growth hormone levels and other short patients who are not growth hormone deficient but who have been given a trial of growth hormone, e.g. those with Silver's syndrome, have not been included.

Altogether there have been 21 patients of this type, 12 with idiopathic growth hormone deficiency $(9$ males and 3 females) and 9 ( 3 males and 6 females) with growth hormone deficiency secondary to known intracranial pathology: 6 craniopharyngiomas, 1 pineal tumour, 1 neurofibroma, and 1 eosinophilic granuloma. The present ages of these patients vary from 7 to 22 years and in the Fig. the distribution of their years of birth are

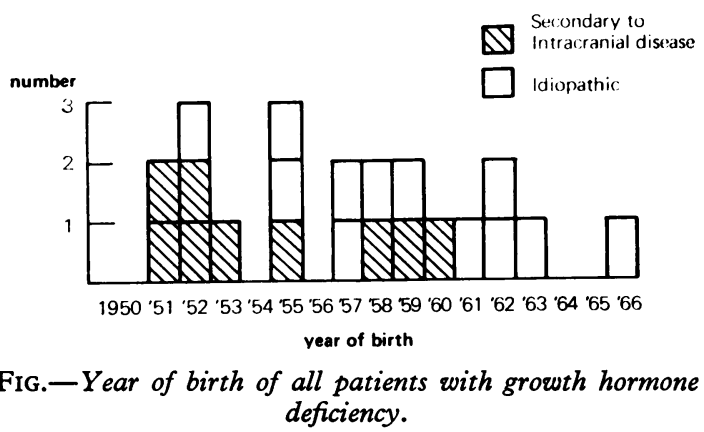

indicated. Secondary growth hormone deficiency is likely to present at an older age than idiopathic, and this is supported by the greater number of such patients in the earlier years.

It is probable that the majority of severely dwarfed children with growth hormone deficiency born between 1951 and 1962 will have presented. Older patients may not have been referred as treatment was not available when they were of the appropriate age, and those born later-especially those with intracranial pathology-may not yet have developed symptoms. During these 12 years 19 growth hormone-deficient patients were born, 10 with idiopathic deficiency and 9 with intracranial pathology. As the annual number of births in the Newcastle region is about 48,000 (Registrar General, 1970) these figures suggest that the annual incidence of growth hormone deficiency is 1 in 30,000 births, approximately half the patients having idiopathic growth hormone deficiency.

Community studies. It is possible that there are children in the community with growth hormone deficiency who are not referred to hospital because either their growth failure is not severe or their parents and doctors do not realize that any treatment is available. The Newcastle Survey of Child Development (G. A. Neligan, personal communication, 1974) has given an opportunity for a study of a total population of short children in Newcastle upon Tyne. All the children who were born in 1960 and whose heights were under the third centile at about 10 years and all the children born in 1961 and 1962 whose heights were more than 3 SDs below the mean at the same age were examined and their growth hormone levels measured after an exercise 